Available online at_www.iponlinejournal.com

\title{
Vitamin D deficiency in term newborn and efficacy of oral vitamin D supplement
}

\author{
Tanmay D Dhanashetti ${ }^{1}$, RH. Gobbur ${ }^{2 *}$, SV. Patil ${ }^{3}$
}

${ }^{1}$ Senior Resident, ${ }^{2}$ Professor and Unit Head, ${ }^{3}$ HOD, Dept. of Pediatric, B.L.D.E University, Vijayapura, Karnataka, India

\begin{abstract}
Introduction: Vitamin D deficiency has emerged as a significant public health problem throughout the world. Even in the Indian context, it has been reported to be present in majority of children in spite of wide availability of sunlight. The manifestations of deficiency are hypocalcaemia seizures of infants, rickets in infancy to tetany in older children. Treatment consists of vitamin D supplementation as Stoss therapy or daily or weekly oral regimens with equal efficacy and safety, combined with calcium supplements. The study was undertaken to determine vitamin D levels in term normal neonates and to observe the efficacy of Single high dose oral Vitamin D therapy. To detect serum vitamin D deficiency/insufficiency in term normal new born and efficacy of oral vitamin D supplement
\end{abstract}

Materials and Methods: 50 term normal new born were randomly selected. Cord blood was collected in plane tube, serum separated and tested for serum vitamin D, calcium, phosphorus and ALP by immune fluorescence assay technique. The babies with the vitamin D deficiency/insufficiency were supplemented with single high dose of vitamin D 60,000 IU given orally. These investigations were repeated after 45 days. This was a Prospective interventional study done between April 2017 to September 2017.

Results: Cord blood serum vitamin D, calcium, phosphorous and ALP levels at the time of birth showed only 5(10\%) babies had normal serum vitamin D levels, 31(62\%) babies had deficiency and14(28\%) babies had insufficiency respectively. Babies with low Vitamin D levels were given single high dose vitamin D 60,000 IU orally. After 45 days serum vitamin D levels were normalized and none of the babies had hypervitaminosis ( $>100 \mathrm{ng} / \mathrm{ml}$ ) with mean serum value of vitamin D was $45.58 \mathrm{mic} / \mathrm{dl}$. Single high dose of vitamin D therapy i.e. 60,000 IU is effective in normalizing the serum vitamin D levels in the babies

Conclusion: Most of our new borns, are born with vitamin D deficiency or insufficiency, and only a few babies have adequate serum vitamin D levels at birth. A single high dose of Oral vitamin D 60,000 IU is sufficient to normalise serum vitamin D levels with none developing hypervitaminosis

Keywords: Vitamin D, Calcium, Vitamin D deficiency, New-born, Dietary supplements, Outcome assessment.

\section{Introduction}

Vitamin D deficiency has emerged as a significant public health problem throughout the world. Even in the Indian context, it has been reported to be present in majority of children in spite of wide availability of sunlight. Recent guidelines have defined vitamin D status as severe deficiency, insufficiency, sufficiency and risk for toxicity as $25(\mathrm{OH}) \mathrm{D}$ levels $<20,<30,>30$ and $>100 \mathrm{ng} / \mathrm{mL}$, respectively. The manifestations of deficiency may vary from hypocalcaemia seizures of infants, rickets in infancy to tetany in adolescence or asymptomatic. Treatment is necessary for all individuals with deficiency whether symptomatic or not. Treatment consisting of vitamin D supplementation as Stoss therapy or daily or weekly oral regimens with equal efficacy and safety, combined with calcium supplements. Routine supplementation starting from new born period is being increasingly endorsed by various international organizations. Adequate sunlight exposure, food fortification and routine supplementation are the currently available options for tackling this nutritional deficiency. Vitamin D is fat soluble, can be stored in liver. Hence high single dose is enough to treat, improving the compliance, unlike water soluble vitamins where daily supplement is required.

\footnotetext{
*Corresponding Author: RH. Gobbur, Dept. of Pediatric, B.L.D.E University, Vijayapura, Karnataka, India

Email: tanumani6@gmail.com

http://doi.org/10.18231/j.ijmpo.2019.022
} 
Table 1: Out of 50 term normal new born status of vitamin D levels at the time of birth shows normal for 5(10\%), deficient for $31(62 \%)$ and inefficient for $14(28 \%)$ of the babies.

\begin{tabular}{|c|c|c|c|c|}
\hline \multicolumn{4}{|c|}{ Status of serum vitamin $\mathbf{d}$ in our 50 babies at birth } & \\
\hline & Normal & Defficient & Insufficient & \\
\hline No. of babies & $5(10 \%)$ & $31(62 \%)$ & $14(28 \%)$ & Total no. Of babies is 50 \\
\hline
\end{tabular}

Table 2: Status of Serum vitamin D level in 50 term normal new born after high dose oral vitamin D therapy i.e. 60000 IU shows vitamin D levels with in normal levels.

\begin{tabular}{|c|c|c|c|c|}
\hline \multicolumn{4}{|c|}{ Serum Vitamin D levels at Follow Up (45 Day) } & \\
\hline & Normal & Defficient & Insufficient & \\
\hline No. of Babies & $50(100 \%)$ & 0 & 0 & Total no. of babies is 50 \\
\hline
\end{tabular}

Vitamin D refers to a group of fat-soluble vitamins, responsible for increasing intestinal absorption of calcium, iron, magnesium, phosphate, and zinc. In humans, the most important compounds in this group are vitamin D3 (also known as cholecalciferol) and vitamin D2 (ergocalciferol). Cholecalciferol and ergocalciferol can be ingested from the diet and from supplements. Very few foods contain vitamin D, mostly animal source. Synthesis of vitamin D (specifically cholecalciferol) in the skin is the major natural source of the vitamin D. Dermal synthesis of vitamin D from cholesterol is dependent on sun exposure (specifically UV radiation), about 60 minutes of exposure to sunlight of half clothed baby. Over one week(Indian Paediatrics). As early as in the 19th century, cod liver oil (a rich source of vitamin D) was used for treating tuberculosis (TB). Skin exposure to sunlight was an effective therapy for treating Mycobacterium infections of the skin in [1903]. Recent studies have linked vitamin D deficiency with increased risk of developing TB, otitis media, upper respiratory tract infections and influenza. ${ }^{1}$

Serum 25(OH)D, has a half-life of about 3 weeks, making it the most suitable indicator of vitamin D status. ${ }^{2}$ 25-hydroxyvitamin D (25OH D) determination is of diagnostic importance for the investigation of vitamin $\mathrm{D}$ deficiency and more rarely, intoxication. Despite the name, vitamin D is a pre-hormone, being endogenously synthesised, provided there is adequate exposure sunlight. Its biological function, exerted through the active form 1,25 Dihydroxy vitamin D3 $(1,25(\mathrm{OH}) 2 \mathrm{D})$ is to maintain calcium and phosphate levels in the blood. In addition, it has important roles in immune regulation. Demand for 25OHD and
$1,25(\mathrm{OH}) 2 \mathrm{D}$ assays has increased substantially worldwide.

K Devaraj naik, remesh preetha, am ramachandran and divianath et al shows that even in a tropical climate, $94 \%$ of term neonates suffer from vitamin D deficiency.

This Study was under taken to determine serum Vitamin D levels in term normal neonates and Efficacy of Single high dose oral, 60,000 IU Vitamin D therapy administered orally.

\section{Materials and Methods}

This was a hospital based prospective interventional study, conducted from April 2017 to September 2017, at shree B.M.Patil medical college and research Centre, vijayapur. Out of 150 neonates born within this period, 25 babies parents didn't give consent, 13 babies were preterm and 7 babies were IUGR.55 babies were excluded (excluded criteria). 1) Known renal, parathyroid hormone abnormality in mother. (maternal parathyroid state was assumed to be normal when her serum calcium, phosphorus levels are normal 2) Mother with Diabetes mellitus and known familial vitamin D resistance like hypophosphatemic rickets. (by any available previous medical records). 3)Baby with severe renal or hepatic disorders, sample was discarded (Renal and hepatic disorder babies was suspected when baby had significant jaundice or severe decreased urine output or established AKD in new born)

Total 50 normal term normal babies were randomly selected. After taking informed consent by the parents. and fulfilling inclusion and exclusion 
criteria, cord blood was collected in plane tube, serum separated and tested for serum vitamin $\mathrm{D}$, calcium phosphorus and ALP by immune assay technique. The values are noted. Then the babies with the vitamin $\mathrm{D}$ deficiency/insufficiency were supplemented with single high dose of vitamin D 60000 IU orally. And followed up after 45 days with estimation of serum vitamin $\mathrm{D}$, calcium phosphorus and ALP. The study was approved by institutional ethics committee [Approval no:61/16].

\section{Statistics}

All characteristics were summarized descriptively. For continuous variables, the summary statistics of mean, standard deviation (SD) were used. Data were analysed using SPSS software v.23.0. and Microsoft office.

\section{Results}

Out of 150 babies delivered in our labour room. 55 babies didn't qualify the inclusion criteria, 25 babies parents didn't give consent 13 babies were preterm and 7 babies were IUGR. Over all 50 babies cord blood was send for serum vitamin $\mathrm{D}$, calcium, phosphorous and ALP levels at the time of birth in that only $5(10 \%)$ babies had normal serum vitamin D levels, $31(62 \%) / 14(28 \%)$ babies had deficiency/insufficiency respectively. Babies with vitamin $\mathrm{D}$ deficiency/insufficiency at the time of birth had given single high dose i.e. 60,000IU of vitamin D orally and follow up has been done after 45 days to check serum vitamin D, calcium, phosphorous and ALP levels. All babies vitamin D levels were normalized and none of the babies had hypervitaminosis $(>100 \mathrm{mg} / \mathrm{dl})$ with serum mean value of vitamin D was $45.58 \mathrm{ng} / \mathrm{ml}$.

$31(62 \%)$ of the neonate have vitamin D deficiency in our population.

$14(28 \%)$ of the neonate have vitamin D insufficiency in our population.

Only $10 \%$ of term neonates have normal Vitamin D status in our population.

Single Oral dose of 60,000 IU Vitamin D normalizes, Vitamin D status in them.

\section{Discussion}

In our study, we aimed to confirm low serum vitamin $\mathrm{D}$ levels in neonates and also the efficacy of vitamin D Single high dose therapy i.e. 60,000 IU ORAL. We assessed the serum levels of vitamin D in neonate born in shree B.M.PATIL Medical college and research centre Vijaypur. According to recent studies, A significant percentage of vitamin D deficiency is noted in the neonate. Vitamin D deficiency has been defined as a $25(\mathrm{OH}) \mathrm{D}$ level less than $20 \mathrm{mg} / \mathrm{ml}(50 \mathrm{nmol} / \mathrm{l})$ while vitamin D insufficiency is defined as a $25(\mathrm{OH}) \mathrm{D}$ level between 21 and $29 \mathrm{ng} / \mathrm{ml}(52-72 \mathrm{nmol} /$ ).

In our study it was found that severe deficiency $(<20 \mathrm{ng} / \mathrm{dl})$ was present in majority of new born $(90 \%)$ whereas with only $10 \%$ babies has normal vitamin D. which was comparable to various studies which have been conducted throughout the world. Kumar P et al found that $83 \%$ of the new-borns had hypovitaminosis with mean cord blood level was $12.8 \mathrm{ng} / \mathrm{dl} .^{3}$ Similar results were found in study done by Khuri $\mathrm{N}$ in Jordan, Park S in Korea, Yu X in China, with deficiency in $94 \%, 91.7 \%, 84.1 \%$ neonates respectively. ${ }^{4,5}$ Sachan A et al found low levels of cord blood $25(\mathrm{OH})$ D $(8.4 \pm 5.7 \mathrm{ng} / \mathrm{mL}){ }^{6}$ Dawodu et al found $44 \%$ of Arab infants had moderately severe deficiency with mean serum vitamin D levels $14.5 \mathrm{nmol} / .^{7}$ Fallahi $\mathrm{M}$ found $56 \%$ of neonates had vitamin D deficiency in Tehran. ${ }^{8}$

In the present study it was found that higher prevalence of vitamin $\mathrm{D}$ deficiency was present in term new born. Total 50 babies were enrolled in this study. Among them 31(62\%)/14(28\%) Babies were vitamin $\mathrm{D}$ deficient/insufficient and $5(10 \%)$ babies were in normal range. All 45 babies low Vit. D were given vitamin D Single high dose therapy i.e. 60'000 IU(ORAL).Gender of the babies were compared and correlate with vitamin D and we found no statistically significant difference found among our study at birth. Mode of delivery of the study babies compared for vitamin $\mathrm{D}$ status at birth, with no statistically significant difference found among our study groups. But study by Gurmeet Singh, Gursharn Singh, Harnoorjit Kaur Brar, Supriya Malik shows that low vitamin D levels in neonates born by LSCS than those delivered by NVD.. Even though we didn't give "Single high vitamin D therapy" to baby having normal serum vitamin $\mathrm{D}$ as it will be unethical. But we believe that even Single high vitamin D therapy in 
babies with normal vitamin D status at birth, will not cause HARM to the babies.

Hence we suggest that larger studies be done to confirm our results (90\% of otherwise normal term babies have Vitamin deficiency at birth.), so that, a single dose Vitamin D at birth will help most babies.

\section{Follow up study in vitamin D therapy}

In our study, mean serum vitamin D levels increased to $45 \mathrm{ng} / \mathrm{ml}$, after supplementation. (Being statistically significant). This proves that single high dose of vitamin D 60,000 IU at birth is very effective, safe and has no toxicity.

\section{Limitation of my study}

Study involved only term new-born. Therefore, it cannot be generalized to preterm and post term neonatal population. Study didn't involve the vitamin D status of the mother. As serum vitamin D status of the mother during pregnancy is significantly correlated with serum vitamin D levels in new-born in some study. We couldn't assess the serum PTH level in any of the babies. Due to the not avability and financial issue. (However may not be required routinely).

\section{Source of Funding}

None.

\section{Conflict of Interest}

None.

\section{References}

1. Nnoaham KE, Clarke A. Low serum vitamin D levels and tuberculosis: A systematic review and meta-analysis. Int $J$ Epidemiol 2008;37(1):113-9.

2. Zerwekh JE. -Blood biomarkers of vitamin D status $1-4$. Am J Clin Nutr 2008;87:1087-91.

3. Kumar P, Shenoi A, Kumar RK, Girish SV, Subbaiah S. Vitamin D deficiency among women in labor and cord blood of newborns. Indian Pediatr 2015;52(6):530-1.

4. Park S, Lee G, Moon J, Kim H. Severe vitamin D deficiency in preterm infants: maternal and neonatal clinical features. Korean J Pediatr 2015;58(11):427-33.

5. Yu X, Wang W, Wei Z, Ouyang F, Huang L. Vitamin D status and related factors in newborns in Shanghai, China. Nutrients 2014;6(12):5600-10.

6. Sachan A, Gupta R, Das V, Agarwal A, Awasthi PK, Bhatia V. High prevalence of vitamin D deficiency among pregnant women and their newborns in northern India. Am J Clin Nutr 2005;81(5):1060-4.

7. Dawodu A, Nath R. High prevalence of moderately severe vitamin D deficiency in preterm infants. Pediatr Int 2011;53(2):207-11.

8. Fallahi M, Afjeh A, Saneifard H, Namazi N, Kazemian M. Comparison of vitamin $\mathrm{D}$ level in preterm and term infantmother Pairs: a brief study. IJN 2016;7(1):32-6.

How to cite this article: Dhanashetti TD, Gobbur RH, Patil SV. Vitamin D deficiency in term newborn and efficacy of oral vitamin D supplement. Int $J$ Med Paediatr Oncol 2019;5(3): 